\title{
Attention Model for Chronic Conditions: Blind Women and Their Sons
}

\author{
Mariana Gonçalves de Oliveira1, Aline Tomaz de Carvalho ${ }^{1 *}$, \\ Lorita Marlena Freitag Pagliuca', Ana Karina Bezerra Pinheiro1, \\ Camila Pontes Bezerra², Márcia Maria Tavares Machado ${ }^{3}$ \\ ${ }^{1}$ Department of Nursing, Universidade Federal do Ceará, Fortaleza, Brazil \\ ${ }^{2}$ Centro Universitário Estácio do Ceará, Fortaleza, Brazil \\ ${ }^{3}$ Department of Community Health, Universidade Federal do Ceará, Fortaleza, Brazil \\ Email: aline.nurse@gmail.com
}

Received 9 May 2015; accepted 22 June 2015; published 26 June 2015

Copyright (C) 2015 by authors and Scientific Research Publishing Inc.

This work is licensed under the Creative Commons Attribution International License (CC BY). http://creativecommons.org/licenses/by/4.0/

c) (i) Open Access

\begin{abstract}
It aimed to analyze the assistance to the blind woman during prenatal care, childbirth, and childcare in light of the Model of Attention to Chronic Conditions. This is a descriptive, qualitative study. A collection was done through semi-structured interview and analysis of the speeches, conducted by content technique proposed by Bardin, emerging from the screening process. Ten mothers aged between 21 and 42 years old participated in the study. Three categories were identified: prescriptive and focused attention on the disease; for collaborative and focused attention on the person; uniprofessional attention to the multidisciplinary attention; establishment of relationship between the family health strategy and the specialized outpatient care. The women experienced chronic conditions according to the Model in addition to blindness. Study results show that for blind women, attention in the health service has weaknesses in service, both in the prenatal period and childbirth, and in childcare. It deems necessary transformation in assisting the blind woman.
\end{abstract}

\section{Keywords}

Blindness, Nursing, Women's Health, Child Health

\section{Introduction}

Global burden of chronic health conditions continues to grow, both globally and in the Americas, requiring more

*Corresponding author.

How to cite this paper: de Oliveira, M.G., de Carvalho, A.T., Pagliuca, L.M.F., Pinheiro, A.K.B., Bezerra, C.P. and Machado, M.M.T. (2015) Attention Model for Chronic Conditions: Blind Women and Their Sons. Health, 7, 747-753.

http://dx.doi.org/10.4236/health.2015.76089 
health systems [1]. In Brazil, the Unified Health System should respond to the needs of this new population profile. However, going through a challenging time ahead to the triple burden of disease, made up by an increase in chronic conditions, the agenda not complete infectious diseases and the increase in external causes. This is exacerbated by the persistent actions in piecemeal health system and facing acute episodes.

Given this, it is necessary to reorganize the system for the construction of the Health Care Networks in the primary health care act strong and resolute manner, user care coordinator and responsible for it. To this end, the Care Model to Chronic Conditions which proposes changes in the way of providing health care was prepared, and how to manage it by incorporating the clinical management, through risk stratification. Chronic conditions are health situations involving maternal and child conditions; conditions linked to the maintenance of health through life cycles (childcare) and continuing physical and structural deficiencies, then inserted blindness.

The Model proposes five levels: 1 ) social determinants of health intermediaries; 2) social determinants of health proximal; 3) individual risks and/or established chronic condition, low and medium risks; 4) established chronic condition, high and very high risk; 5) very complex health conditions. Here we adopted the level 3 model, which features nine dimensions: I) The prescriptive and focused attention on the disease for collaborative and focused attention on the person; II) The attention focused on the individual to focusing attention on the family; III) The strengthening of supported self-care; IV) The balance between attention to spontaneous demand and scheduled attention; V) From uniprofessional attention to the multidisciplinary attention; VI) The introduction of new forms of professional attention; VII) The establishment of new forms of relationship between the Family Heatlh Strategy (FHS) and the specialized outpatient care; VIII) The balance between classroom and non-classroom attention; IX) The balance between professional care and attention by laymen [2].

Blind person is one who has an irreversible situation of visual function of congenital or acquired origin [3]. Blind women beget children, and have need of information and professional support before and after birth [4]. Blind clientele find many obstacles in social integration because of the unpreparedness of society causing numerous barriers of different kinds [5]. Since the blind person is able to care for themselves and their children, even in need of family support and health care team. In this context, it is for health services promote this right, through holistic care, humane, carefully, accessible information and guidance.

Thus, as a contribution to in-depth discussion, this study aims to analyze assistance to the blind woman during follow-up in the prenatal and parturition and to his son in childcare in the light of Care model for Chronic Conditions (MACC).

\section{Method}

This is a descriptive, qualitative study conducted in the state of Ceará. Population composed by blind mothers, non-probabilistic sample obtained intentionally resorting to snowball technique [6] used in social surveys where people initially interviewed indicate new participants, until saturation is reached.

Inclusion criteria are mothers with children 0 - 10 years of age and residents of the city of Fortaleza, from March to July 2013. Data collected by semi-structured interview, at home or workplace using recording for reliability of verbalized reports. Later, transcripts of speeches, repeated readings of interviews and analysis of employment data conducted by content technique proposed by Bardin, emerging from the screening process [7].

This method is described in the analysis of content, from the interviews in order to observe the differences and confluences presented by the participants, and so group them into categories. The methodological path is based on three steps: pre-analysis; use of data; and treatment outcome [7].

Project respected international research precepts with human beings, approved by the Ethics Committee of the Federal University of Ceará-UFC-COMEP under the opinion No. 237/07. Participants signed an informed consent form after reading the interviewer with the presence of the blind mother reliable witness.

\section{Results}

A total of ten blind mothers, aged between 21 and 42 years old participated. Six women to complete high school, three with incomplete primary education and a college. Eight women were married, family income of US \$370, predominated cesarean section. To preserve anonymity used the letter E (respondents), and the number of 1 to 10.

They were selected from three categories of the theoretical framework: 1) the prescriptive and focused attention on the disease for collaborative and focused attention on the person; 2) from uniprofessional attention to the 
multidisciplinary attention; 3) the establishment of new forms of relationship between the FHS and the specialized outpatient care.

\subsection{Prescriptive and Focused Attention on the Disease to the Person-Centered Collaborative Care}

Mothers report that prenatal visit was limited to routine physical examinations, such as measuring waist circumference, weight assessment and baby auscultation without guidance on maternal and child care:

Then she put (tape) and measured the belly and heard the heart of the baby and see if everything was fine with it (E1);

There was no guidance, it went from me. Well, I had no knowledge, had never seen any nursing child. (E6);

Regular service. I arrived there was a prenatal consultation and leave. He did not speak, did not talk anything (E4);

...In pregnancy no explanation had not ... I did not talk about breastfeeding. He spoke only about rest, but beware of the baby does not (E6);

Mothers describe their moments of reaching the hospitals, indicating the lack of clarification about the presence of a partner, the labor, the psychosocial conditions, highlighting the lack of a holistic and humanized care by health professionals, as has noted:

Then she said, you could expect to have normal, but is more suffering, for both you and for the baby (E4);

No, no one came to me to the birth; my husband left me outside and left (E8);

Then I was in a room alone without assistance. The only companion I had the night when I had the baby. I found it sad, too cold, you feel abandoned, comes the person just to give you scolding because you get to moan due to nervousness, it is neither because of the pain. It is the nervousness that gives you seeing everyone having baby and you do not (E6);

After the birth of their children during the child-care consultation, it has been reported difficulties with regard to respect for the autonomy of these mothers:

Because they do not understand that we can go to the clinic with her son alone, they think we have an obligation to take a person who sees (E2);

The staff wanted me to quit my guide go with my son because I was blind, I fought because the child was mine, who had to go was me, they thought because I'm blind could not keep up (E9).

\subsection{From the Uniprofessional Attention to the Multidisciplinary Attention}

During routine visits carried out by the doctor, the uniprofessional attention proved to be short-lived, what generated dissatisfaction from the mothers:

At the first visit I did not like it much. It was very quick. He just asked if the child was eating well, but did not examine the child (E3);

I think that leaves much to be desired. It is quite closed. They do not have much time to the child (E2);

However, immunization services provided by the nursing team, was reported satisfaction:

When I went to give him the vaccine, the nurse talked enough. She explained to me what I could do with it if by chance got too sick with the thigh vaccine. I liked (E1);

Treat well. Nurses do everything to not separate the baby from me, because the greatest fear I have is separate from them (E7).

\subsection{The Establishment of New Forms of Relationship between the FHS and the Outpatient Specialized Attention}

During prenatal care, blind mothers reported that, in the basic health unit headed the professionals, in the first few visits to a secondary or tertiary level institution. Blind women were considered a population at risk for a premature birth or some other complication:

... here at the station ... said they would not be able to stay with me ... It was a doctor who said he would not be with me because I was that way (blind), I was very straight was poor and everything, so she I thought I would not be able to have a child and had the child was born six months (E1);

In the first prenatal consultation they sent me go to the hospital because there I was able to make faster ex- 
ams (E5).

\section{Discussion}

Blind women experienced several chronic conditions according to the MACC addition to blindness, such as prenatal care and childbirth, and after the birth of their children, monitoring for child care. Given these experiences were observed some aspects related to the need for reorganization of the Unified Health System (SUS), which needs to change so you can achieve with effectiveness, efficiency and safety to health moments tamed by chronic conditions [8].

Regarding knowledge about the blind woman, the National Policy of Health Person with Disabilities said that professionals must be able to satisfy this clientele [9]. This becomes important for the increase in resolution of the teams on the care of blind people [10]. However, these women should be involved throughout the process of care, and receive information about their health condition as well as being prepared to make decisions about you. With this, it becomes clear that in addition to proactive and prepared teams, the change in service requires the participation of active and informed users [11].

While it is clear need for involvement of patients throughout the care process, insufficient recognition of the human dimension in health remains an important gap in attention to contemporary health, which creates inequities and poor health outcomes. Antagonistic to this, people should be treated holistically with an appreciation of their physical, social, emotional problems, his past and his future and the realities of the world in which they live [12].

The reform in health care models in favor of APS aims to place people at the center of attention so that services are effective, efficient and equitable. A process that begins with the close and direct relationship between individuals and their communities and their dispensers' attention, which leads to better health outcomes [12].

However, while the advancement of medicine has brought health for improvement, it has inadvertently increased the distance between professionals and their patients. This creates an environment where users and their families are excluded from important discussions and are overlooked about their problems and their management as well as on treatments and diagnostics available for their choice [13].

The experience of front blind woman to prenatal consultations and their children during child care, there was a predominance of dissatisfaction reports and has pointed the need for more in-depth information offered by the professionals involved. This educational process should occur throughout the pregnancy cycle, involving the blind woman and her family, which provides security and satisfaction in childbirth. Similarly, the routine visits should be enlightening character and involve the family participation.

Study on the effects of prenatal education on birth showed that the education of women in this period helps to increase understanding of their role in this process, increases the sense of control and satisfaction with the birth experience [14]. In the transition period for postpartum and during routine visits this support has a positive impact on maternal efficiency, especially for gilts [15].

It is clear, therefore, the need for assistance aimed at the blind woman and their needs addressed in periods. However, the results of this study point to hospital-centered care, focused on illness and professional, with obvious fragmentation of attention. Study line with these findings, as compared medical attitudes of four specialties and found that obstetricians and gynecologists tend perform their conduct focused more on themselves than on the patient when compared to general practitioners [16].

Despite delivery constitute a routine in hospitals and maternity wards, every woman should receive differentiated service where care and comfort should be provided aiming the uniqueness of each woman in labor [17].

It is also realized the need for emotional support and alleviation of fear and anxiety present as a result of childbirth. This support is important because the fear and anxiety associated with a health condition can be as debilitating as the physical effects 17 . Evidence demonstrated that there is feeling of loneliness in childbirth for some women and that this experience increases fear, which can be reduced when answered the expectations and needs of this woman through professional support [18].

In assistance to child health, we seek to promote and restore health and child well-being in order to ensure proper growth and development in the physical, emotional and social aspects. The childcare contributes to health promotion strategies in the waiting room and during the consultation, providing monitoring of mother and child, so as to give rise to exchange of experiences and overcoming difficulties [19].

The blind mother finds barriers as understanding and appreciation of their autonomy. This is able to care for 
their children which imply on the understanding of health professionals on the subject, which is not well known. The family should be included in monitoring their children so that assistance is safe and effective, with strengthening of its autonomy and independence [20].

Study found that the blind parents find strategies to care for their children who rely on the remaining senses (touch, smell and hearing) and the use of support networks, as a mother, sister or community was essential for assistance in caring for blind mother [21]. With this, it highlights the importance of valuing the autonomy of these women according to their limitations as well as the front Family integration to children's health.

As rapid consultations referred to by users, these can be supplemented by multidisciplinary care, dispensed by teams working in coordination-based care plans. Team members must share a common goal for a sacrifice of his professional autonomy and enable coordinated activity by the team [22].

These teams should include the person who is the focus of care, in the same way that the health professionals involved. These meetings can take place before or after the consultations of 15 minutes commonly present in Primary Health, allowing continuity of care as well as additional questions for clarification opportunities and expectations of women [23].

During prenatal care, it was shown that there is a need for staff training of Primary Health Care (PHC) to meet the blind women in all its needs, without referring them immediately to the secondary or tertiary care centers. For this, the new model of care calls for professionals to act in an integrated manner in order to ensure the patient what they need, when they need to, as best as possible [24].

Therefore, a reorganization of the relationship between the APS and the Specialized Ambulatory Care (SEA) it is necessary in order to migrate from completely fragmented care (in silos) currently in effect, to the coordination of care, which requires the team to participate multidisciplinary, close relationship between generalists and specialists, user participation and the participation of a case manager, all with the coordination of APS [25].

Thus it is possible to provide less costly care, better quality and more targeted to respond to chronic diseases, the increasing prevalence and little responsive to contemporary medical attention, fragmented by progressive specialization and even organized to respond to acute problems, not ensuring attention integral to chronic patients [26].

Furthermore, it should be strengthened coordination function of APS, which the general is primarily responsible for the user, able to provide resolute service quality. This should take filter paper (gatekeeping), related to the management and accountability for therapeutic User path [10]. This requires training focused on community and family, both graduations, and in continuing education, which is configured as another challenge in changing the attention [26].

\section{Conclusions}

Study results show that for blind women, attention in the health service has weaknesses in service, both in the prenatal period and childbirth, and in childcare. Based on the reports of the blinds in the light of MACC, it can be seen opposite changing needs immediate reference of the general to the expert, the lack of information during the prenatal, childbirth and childcare, as well as the lack of emotional support during childbirth. It was also reported to devaluation and lack of encouragement of autonomy of these women to care for their children and the importance of replacing the uniprofessional attention, with early consultation to multidisciplinary monitoring.

It can be seen so it is essential to change fragmented health services to the coordinated care with assistance to blind women in prenatal care and childbirth, and his son in childcare consultation happen humanistic, effectively and efficiently. These changes necessarily involve the training of health professionals to deal with the blind client.

This study deals with a qualitative approach, which does not intend to generalize their results. Because it is a group of blind mothers, the results cannot be extended to the entire population of blind city of Fortaleza. However, it can point out peculiar issues to this population that need to be reflected in the attention to public health of this group in particular.

\section{Acknowledgements}

This study was made possible through a grant from the Coordination of Improvement of Higher Education Personnel (CAPES) and the National Council for Scientific and Technological Development (CNPq). 


\section{References}

[1] Organización Panamericana de la Salud (2013) Cuidados innovadores para las condiciones crónicas: Organización y prestación de atención de alta calidad a las enfermidades crónicas no transmisibles en las Américas. http://www.paho.org/hq/index.php?option=com_docman\&task=doc_view\&gid=22257+\&Itemid=999999\&lang=es

[2] Mendes, E.V. (2012) O cuidado das condições crônicas na atenção primária à saúde: O imperativo da consolidação da estratégia da saúde da família. Organização Pan-Americana da Saúde, Brasília. http://bvsms.saude.gov.br/bvs/publicacoes/cuidado_condicoes_atencao_primaria_saude.pdf

[3] World Health Organization (2012) Definitions of Blindness and Visual Impairment. http://www.who.int/mediacentre/factsheets/fs282/en/

[4] de Oliveira, M. and Pagliuca, L. (2014) Construction of Assistive Technology for Blind Women: Handbook on Behavioral Contraceptive Methods. Creative Education, 5, 1979-1983. http://dx.doi.org/10.4236/ce.2014.523222

[5] Pagliuca, L.M.F., et al. (2014) Validation of the General Guidelines of Communication between the Nurse and the Blind. Revista Brasileira de Enfermagem, 67, 715-721. http://dx.doi.org/10.1590/0034-7167.2014670507

[6] Sousa, Z.A.A., Silva, J.G. and Ferreira, M.A. (2014) Knowledge and Practices of Teenagers about Health: Implications for the Lifestyle and Self Care. Escola Anna Nery, 18, 400-406. http://www.scielo.br/scielo.php?script=sci_arttext\&pid=S1414-81452014000300400\&lng=en\&nrm=iso

[7] Bardin, L. (2011) Análise de conteúdo. Edições 70, Lisboa.

[8] Mendes, E.V. (2010) As redes de atenção à saúde. Rev Ciência Saúde Coletiva, 15, 2297-2305. http://dx.doi.org/10.1590/S1413-81232010000500005

[9] Brasil Ministério da Saúde (2010) Política Nacional de Saúde da Pessoa com Deficiência. Ministério da Saúde, Brasília. http://bvsms.saude.gov.br/bvs/publicacoes/politica_nacional_pessoa_com_deficiencia.pdf

[10] Almeida, P.F., Fausto, M.C.R. and Giovanella, L. (2011) Strengthening Primary Health Care: A Strategy to Maximize Coordination of Care. Revista Panamericana de Salud Pública, 29, 84-95. http://www.scielosp.org/scielo.php?script=sci_arttext\&pid=S1020-49892011000200003\&lng=pt http://dx.doi.org/10.1590/S1020-49892011000200003

[11] de Andrade, F.B., Costa, I.C.C., dos Santos Ferreira, T.L., Justino, D.C.P., de Medeiros Souza, L.R., Fonsêca, C.J.B., et al. (2015) Quality of Service to Users of Primary Health Care: A Study of Evaluation. Health, 7, 201-206. http://dx.doi.org/10.4236/health.2015.72023

[12] World Health Organization (2013) The World Health Report 2013: Research for Universal Health Coverage. http://apps.who.int/iris/bitstream/10665/85761/2/9789240690837 eng.pdf?ua=1

[13] Barry, M.J. and Edgman-Levitan, S. (2012) Shared Decision Making-The Pinnacle of Patient-Centered Care. New England Journal of Medicine, 366, 780-781. http://www.nejm.org/doi/full/10.1056/NEJMp1109283 http://dx.doi.org/10.1056/NEJMp1109283

[14] Schmalfuss, J.M., Prates, L.A., de Azevedo, M. and Schneider, V. (2014) Diabetes Melito Gestacional e as Implicações para o Cuidado de Enfermagem no Pré-Natal. Cogitare Enfermagem, 19, 815-822. http://ojs.c3sl.ufpr.br/ojs/index.php/cogitare/article/view/36398

[15] Rowe, J., Barnes, M. and Sutherns, S. (2013) Supporting Maternal Transition: Continuity, Coaching, and Control. The Journal of Perinatal Education, 22, 145-155. http://www.ncbi.nlm.nih.gov/pmc/articles/PMC4010236/ http://dx.doi.org/10.1891/1058-1243.22.3.145

[16] Chan, C.M. and Ahmad, W.A. (2012) Differences in Physician Attitudes towards Patient-Centredness: Across Four Medical Specialties. International Journal of Clinical Practice, 66, 16-20.

http://www.ncbi.nlm.nih.gov/pubmed/22171901 http://dx.doi.org/10.1111/j.1742-1241.2011.02831.x

[17] d’Orsi, E., Brüggemann, O.M., Diniz, C.S.G., de Aguiar, J.M., Gusman, C.R., Torres, J.A., et al. (2014) Desigualdades sociais e satisfação das mulheres com o atendimento ao parto no Brasil: Estudo nacional de base hospitalar. Cadernos de Saúde Pública, 30, S154-S168.

http://www.scielo.br/scielo.php?script=sci_arttext\&pid=S0102-311X2014001300021\&lng=pt http://dx.doi.org/10.1590/0102-311x00087813

[18] Alves, V.C. (2014) Humanization of Nursing Care in Prenatal. Revista Enfermagem Profissional, 1, 471-488. http://www.seer.unirio.br/index.php/enfermagemprofissional/article/view/3362

[19] Vasconcelos, V.M., Frota, M.A., Martins, M.C. and Machado, M.M.T. (2012) Child Care in Nursing and Health Education: Mother's Perception in Family Health Strategy. Escola Anna Nery, 16, 326-331. http://www.scielo.br/scielo.php?script=sci_arttext\&pid=S1414-81452012000200017\&lng=en http://dx.doi.org/10.1590/S1414-81452012000200017

[20] Jorge, H.M.F., Bezerra, J.F., Oriá, M.O.B., Brasil, C.C.P., Araujo, M.A.L. and Silva, R.M. (2014) The Ways in Which 
Blind Mothers Cope with Taking Care of Their Children under 12 Years Old. Texto \& Contexto-Enfermagem, 23, 1013-1021. http://dx.doi.org/10.1590/0104-07072014002920012 http://www.scielo.br/scielo.php?script=sci_arttext\&pid=S0104-07072014000401013\&lng=en

[21] Pagliuca, L.M.F., Uchoa, R.S. and Machado, M.M.T. (2009) Blind Parents: Their Experience in Care for Their Children. The Revista Latino-Americana de Enfermagem, 17, 137-139. http://www.scielo.br/pdf/rlae/v17n2/pt 21.pdf

[22] Clements, D., Dault, M. and Priest, A. (2007) Effective Teamwork in Healthcare: Research and Reality. Healthcare Papers, 7, 26-34. http://www.ncbi.nlm.nih.gov/pubmed/17478997 http://dx.doi.org/10.12927/hcpap.2013.18669

[23] Dancer, S. and Courtney, M. (2010) Improving Diabetes Patient Outcomes: Framing Research into the Chronic Care Model. Journal of the American Academy of Nurse Practitioners, 22, 580-585. http://www.ncbi.nlm.nih.gov/pubmed/21054631 http://dx.doi.org/10.1111/j.1745-7599.2010.00559.x

[24] Handell, I.B.S., Cruz, M.M. and Santos, M.A. (2014) Evaluation of Antenatal Care in Selected Family Health Centres in a Midwest Brazilian Municipality, 2008-2009. Epidemiologia e Serviços de Saúde, 23,101-110. http://scielo.iec.pa.gov.br/scielo.php?script=sci_arttext\&pid=S1679-49742014000100010\&lng=pt http://dx.doi.org/10.5123/S1679-49742014000100010

[25] Oprea, L., Braunack-Mayer, A., Rogers, W.A. and Stocks, N. (2010) An Ethical Justification for the Chronic Care Model (CCM). Health Expectations, 13, 55-64. http://www.ncbi.nlm.nih.gov/pubmed/19906213 http://dx.doi.org/10.1111/j.1369-7625.2009.00581.x

[26] Giovanella, L. (2011) Networks, Disease Management Programs, GP Coordinator: Analysis of Recent Ambulatory Reforms in Germany. Ciência \& Saúde Coletiva, 16, 1081-1096. http://www.scielo.br/scielo.php?script=sci_arttext\&pid=S1413-81232011000700040\&lng=en http://dx.doi.org/10.1590/S1413-81232011000700040 